\title{
Chapter 20 \\ Critical Steps for Engaging Hispanics in Cancer Research: Building Capacity to Enhance Participation in Biospecimen Donation with Hispanic Communities
}

\author{
Elisa Marie Rodriguez and Deborah O. Erwin
}

\section{Introduction}

The disproportionately lower number of certain subpopulations participating in clinical and prevention research has a significant impact on the representativeness of scientific outcomes and results in social and clinical injustices [1]. A sequential set of community-based studies were conducted to engage diverse medically underserved populations in biospecimen donation for cancer genomic research $[2,3]$. This chapter is organized around three critical steps of community engagement that are relevant to participatory research as applied to novel and formative efforts focused on biospecimen science that were used in the Hoy y Mañana (translated to Today and Tomorrow) study. Specifically, these studies developed and tested community-based interventions to identify influential factors regarding participation in biospecimen donation to a biorepository at a cancer center in upstate New York for future cancer research from a Northeast Hispanic, predominantly Puerto Rican population [4].

\section{Three Critical Steps for Engaging Hispanics in Cancer Research}

Community engagement is an essential component to reaching and including diverse andlor hard-to-reach populations in biomedical research with a focus on reducing health disparities and improving individual health. There are three overarching steps that can be applied when working at the community level that facilitate

E. M. Rodriguez, PhD, MS $(\bowtie) \cdot$ D. O. Erwin, PhD

Department of Cancer Prevention and Control,

Roswell Park Comprehensive Cancer Center, Buffalo, NY, USA

e-mail: Elisa.Rodriguez@ roswellpark.org 
engaged approaches to research and enhance the relevance of research as an opportunity to build capacity and increase health equity. The following steps are not exclusive to biospecimen research studies but can be applied to a variety of public health issues and research topics targeting efforts at a community level.

\section{Step 1: Know the Community}

The first step is to know the community. Knowing the community requires an indepth understanding of community members and stakeholders, barriers and assets, population demographics, and community context. The Community Development Model for Public Health Applications is a comprehensive model that integrates the factors essential to knowing a community as the primary unit of analysis and can be used as a framework to guide community-engaged research efforts [5]. Additionally, Community-Based Participatory Research (CBPR) principles and methods also serve as a foundation for collaborative approaches to research that enhance and support community engagement research activities across a variety of topics and disciplines.

Involving the community at the earliest stages of the research process can better ensure acceptability and relevance to the population of interest. The Hoy y Mañana (HyM) study focused on the opportunity to build capacity with preexisting community partners around the topic of biospecimen donation for future cancer research [3]. Capacity building is a key component of the CBPR principles that values skill building and co-learning [6]. Community partners played an integral role in linking the pilot research project to the community and vice versa. Transparent and consistent communication was an important factor throughout the process and contributed to an effective partnership process in engaging the community and assessing feasibility to conduct community-based cancer research involving the collection of biospecimens.

Formative research including structured in-person interviews and focus groups were completed with Hispanic community leaders, staff from the biorepository at the cancer center, and Hispanic participants from the community. Table 20.1 provides examples of the qualitative methods employed in the HyM study to illustrate the process used to gain the community perspective regarding biospecimen donation for cancer research and how the data informed each step of the research. The key informant interviews with Hispanic community leaders were part of the first level of community data collection. These individuals are best described as community leaders (e.g., pastors, civic leaders, and clinicians who practice in the community). They are trusted individuals who often assume an informal gatekeeper role in the community because of their established relationships with members of the community at large. Knowledge of the community facilitates an understanding of who these respected and trusted leaders are and the potential impact they can have in linking the community to collaborative research opportunities. Rodriguez et al. describe the methods and community-engaged research process in detail as well as 
Table 20.1 Summary of formative research methods used in the Hoy y Mañana study

\begin{tabular}{|c|c|c|c|}
\hline Objective & $n$ & Method & Findings (examples) \\
\hline \multirow{5}{*}{$\begin{array}{l}\text { Gain perspective of Hispanic } \\
\text { community leaders }\end{array}$} & \multirow[t]{5}{*}{6} & \multirow{5}{*}{$\begin{array}{l}\text { Structured } \\
\text { in-person key } \\
\text { informant } \\
\text { interviews }\end{array}$} & Lack of awareness \\
\hline & & & How are specimens used? \\
\hline & & & Never asked to donate \\
\hline & & & Integration/application: \\
\hline & & & $\begin{array}{l}\text { These findings informed focus group } \\
\text { topics with broader community }\end{array}$ \\
\hline \multirow{3}{*}{$\begin{array}{l}\text { Gain perspective of } \\
\text { biorepository staff at the } \\
\text { cancer center }\end{array}$} & \multirow[t]{3}{*}{5} & \multirow{3}{*}{$\begin{array}{l}\text { Structured } \\
\text { in-person } \\
\text { interviews }\end{array}$} & $\begin{array}{l}\text { Identified staffing needs to ensure } \\
\text { community competence }\end{array}$ \\
\hline & & & Integration/application: \\
\hline & & & $\begin{array}{l}\text { Informed protocol for collecting } \\
\text { samples in the community to maintain } \\
\text { scientific rigor while enhancing } \\
\text { community access to participation in } \\
\text { biospecimen donation }\end{array}$ \\
\hline \multirow{5}{*}{$\begin{array}{l}\text { Identify barriers and assets in } \\
\text { recruiting diverse populations } \\
\text { to biospecimen donation } \\
\text { (e.g., Hispanic community) }\end{array}$} & \multirow[t]{5}{*}{24} & \multirow{5}{*}{$\begin{array}{l}\text { Focus groups } \\
(n=4) \text { with } \\
\text { participants from } \\
\text { the community }\end{array}$} & Lack of awareness \\
\hline & & & Interest in research opportunities \\
\hline & & & $\begin{array}{l}\text { Need for translated materials and } \\
\text { consent process }\end{array}$ \\
\hline & & & Integration/application: \\
\hline & & & $\begin{array}{l}\text { Disseminated results to community } \\
\text { advisors and informed the design of a } \\
\text { community-based pilot }\end{array}$ \\
\hline
\end{tabular}

the resultant findings from a predominantly Puerto Rican population with regard to their self-reported awareness and interest in biospecimen donation for cancer research [3].

\section{Step 2: Know the Goal of Engagement Activities}

Community-engaged research efforts often require understanding and commitment to an iterative process; however, the goal of engagement activities should be transparent and mutually agreed upon prior to research implementation to ensure acceptance and commitment to the process. In the HyM study, the objective of this first step was to better understand the community's awareness, knowledge, attitudes, and interest in biospecimen donation for cancer research. The results from the formative research were shared with stakeholders including the Community Advisory Board $(\mathrm{CAB})$ members during a partner education component of the study to finalize concepts to be covered in the biospecimen science education program. Dissemination activities require thoughtful planning, because there may be different audiences (e.g., CAB and community members) and time points within the research process that require their own feedback loops for sharing information as it is developed and analyzed. Likewise, how information is developed and analyzed requires 


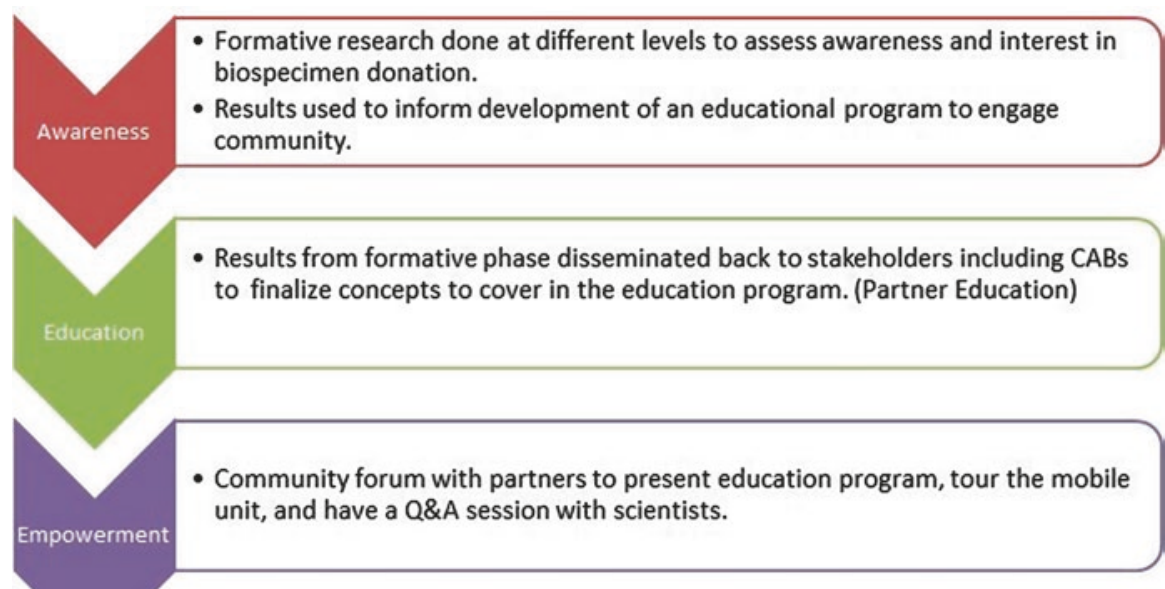

Iterative process as we needed to engage our community on two levels:

1) Gatekeepers and 2) Community

Fig. 20.1 Study schematic describing examples during each phase of the research process: (1) Formative phase: assess awareness; (2) development phase: create a culturally appropriate biospecimen science education program to deliver in the community; (3) implementation: test the education program and feasibility of mobile lab unit to facilitate community participation in biospecimen donation for cancer research

consideration of the goal and transparency in why and how specific partners are included throughout the research process.

The HyM study involved multiple phases that fed into each other and led to the testing of a mobile lab unit that could be used to collect and process biospecimen donations from willing community members at onsite events in the community. Each phase of the research included specific activities and processes that were meant to assess, deliver, or support the intended research goals of the study (Fig. 20.1).

\section{Step 3: Design Activities Using Best Practice Strategies}

As with any type of research, there is an emphasis on scientific rigor and the process applied to draw conclusions from study findings. Community-based research will often vary with respect to the level of community partner involvement, and this is unique to each collaboration; however, in studies that apply CBPR methodology, there are accepted and best practice strategies that can be used to ensure scientific rigor while addressing the issues most relevant to the community [6]. Best practice strategies should be applied at all phases of the research process and considered as an opportunity to further integrate community partners as citizen scientists who are the rightful experts with respect to the communities they live in. 
Table 20.2 Application of best practices in the Hoy y Mañana (HyM) study

\begin{tabular}{l|l}
\hline $\begin{array}{l}\text { HyM study } \\
\text { component }\end{array}$ & Best practice strategies applied \\
\hline Study design & Community-Based Participatory Research (CBPR) Approach \\
\hline Implementation & Informed by CBPR principles \\
\hline $\begin{array}{l}\text { Assessment/collect } \\
\text { data }\end{array}$ & Mixed methods \\
\hline Culture and literacy & $\begin{array}{l}\text { All program materials were translated to Spanish to meet community } \\
\text { language needs and preferences }\end{array}$ \\
\cline { 2 - 2 } & $\begin{array}{l}\text { An Audience Response System was used to engage the community } \\
\text { audience in the educational presentation and facilitate an interactive } \\
\text { survey process }\end{array}$ \\
\hline $\begin{array}{l}\text { Evaluation and } \\
\text { refinement }\end{array}$ & Revisions were made after multiple pilot programs \\
\cline { 2 - 2 } & Spanish translation and verification process \\
\cline { 2 - 2 } & $\begin{array}{l}\text { Process measures were collected on efficacy of the community pilot } \\
\text { including implementation of tools and the mobile unit }\end{array}$ \\
\hline $\begin{array}{l}\text { Public } \\
\text { dissemination }\end{array}$ & Hispanic newspapers and radio \\
\hline
\end{tabular}

The HyM study applied best practice strategies throughout each component of the research process from study design to public dissemination (Table 20.2). The CBPR principles were followed from the onset of the grant writing process and applied to all steps of the educational tool development, implementation, and dissemination processes [7]. Ultimately the application of a CBPR approach served to broker communication among scientists and community stakeholders and members throughout the biospecimen science co-learning process. An important implication included a detailed understanding of methods for introducing biospecimen science to diverse communities such as the Hispanic community engaged in the HyM study.

\section{Discussion and Lessons Learned}

Hispanics represent a significant proportion of the diverse minority populations that make up the United States and are underrepresented in biomedical research studies and even more so in biospecimen banks [8,9]. A growing number of cancer research studies include the collection of biospecimens as part of the research participation process. It is important that this rapidly evolving field of cancer research as it relates to precision medicine and/or immunotherapy not contribute to further gaps and disparities across the cancer care and research spectrum. The HyM study sought to engage and partner with an underserved Hispanic community to (1) understand their awareness and interest in biospecimen science (2) develop a community-based education program to increase awareness and facilitate informed decision-making with regard to biospecimen donation and (3) test the feasibility of communityengaged culturally appropriate approaches in recruiting diverse and underserved 
community participants to biospecimen donation for cancer research using a mobile lab unit for onsite collection and processing of biospecimen donations.

Most Hispanic groups do not have a historical context of mistrust with regard to the medical community. Other studies including Hispanics have also found that lack of awareness regarding biospecimen science and/or not having been asked to participate in cancer research are the primary reasons cited by this population regarding their lack of participation in biospecimen donation $[2,4,9]$. Cancer research opportunities inclusive of Hispanics are critical to understand the molecular differences in cancer cells compared to populations that have been better studied and represented in research [10]. Community-engaged studies have shown that several Hispanic groups indicate a willingness to donate biospecimens for cancer research and also support the use of trained non-medical staff to obtain consent for the biospecimen request $[2,11]$. Engaging Hispanic communities in a culturally appropriate manner at the very beginning is necessary and essential to the collection of biospecimens for cancer research. This research requires a commitment to collaboration across disciplines and values community engagement as part of the research process.

\section{References}

1. Katz RV, Wang MQ, Green BL, Kressin NR, Claudio C, Russell SL, et al. Participation in biomedical research studies and cancer screenings: perceptions of risks to minorities compared with Whites. Cancer Control. 2008;15(4):344-51.

2. Rodriguez EM, Saad-Harfouche FG, Miller A, Mahoney MC, Ambrosone CB, Morrison CD, et al. Engaging diverse populations in biospecimen donation: results from the Hoy y Manana study. J Community Genet. 2016;7(4):271-7. https://doi.org/10.1007/s12687-016-0275-3.

3. Rodriguez EM, Torres ET, Erwin DO. Awareness and interest in biospecimen donation for cancer research: views from gatekeepers and prospective participants in the Latino community. J Community Genet. 2013;4(4):461-8. https://doi.org/10.1007/s12687-013-0152-2.

4. Dang JH, Rodriguez EM, Luque JS, Erwin DO, Meade CD, Chen MS Jr. Engaging diverse populations about biospecimen donation for cancer research. J Community Genet. 2014;5(4):31327. https://doi.org/10.1007/s12687-014-0186-0.

5. Robinson RG. Community development model for public health applications: overview of a model to eliminate population disparities. Health Promot Pract. 2005;6(3):338-46. https://doi. org/10.1177/1524839905276036.

6. Parker EA, Robins T, Israel B, Brakefield-Caldwell W, Edgren K, Wilkins D, et al. Methods in community-based participatory research for health. San Francisco: Jossey-Bass; 2005.

7. Meade CD, Rodriguez EM, Arevalo M, Luque JS, Harris N, San Miguel G, et al. Introducing biospecimen science to communities: tools from two cities. Prog Community Health Partnersh. 2015;9(Suppl):51-9. https://doi.org/10.1353/cpr.2015.0024.

8. Lopez DS, Fernandez ME, Cano MA, Mendez C, Tsai CL, Wetter DW, et al. Association of acculturation, nativity, and years living in the United States with biobanking among individuals of Mexican descent. Cancer Epidemiol Biomarkers Prev. 2014;23(3):402-8. https://doi. org/10.1158/1055-9965.Epi-13-0747.

9. Partridge E. Yes, minority and underserved populations will participate in biospecimen collection. Cancer Epidemiol Biomarkers Prev. 2014;23(6):895-7. 
10. Mora E, Robb JA, Stefanoff G, Mellado RH, Coppola D, Munoz-Antonia T, et al. Proceedings of the 1st Puerto Rico Biobanking workshop. Rev Recent Clin Trials. 2014;9(4):233-44.

11. Nodora JN, Komenaka IK, Bouton ME, Ohno-Machado L, Schwab R, Kim HE, et al. Biospecimen sharing among hispanic women in a safety-net clinic: implications for the precision medicine initiative. J Natl Cancer Inst. 2017;109(2). https://doi.org/10.1093/jnci/djw201.

Open Access This chapter is licensed under the terms of the Creative Commons AttributionNonCommercial 4.0 International License (http://creativecommons.org/licenses/by-nc/4.0/), which permits any noncommercial use, sharing, adaptation, distribution and reproduction in any medium or format, as long as you give appropriate credit to the original author(s) and the source, provide a link to the Creative Commons license and indicate if changes were made.

The images or other third party material in this chapter are included in the chapter's Creative Commons license, unless indicated otherwise in a credit line to the material. If material is not included in the chapter's Creative Commons license and your intended use is not permitted by statutory regulation or exceeds the permitted use, you will need to obtain permission directly from the copyright holder.

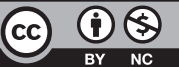

